\title{
An Interview with Daniel Kahneman
}

\author{
Princeton University
}

\author{
Interview by \\ Aaron Jarden \\ 16 December 2010
}

\section{What got you interested in wellbeing research?}

I got interested through the work I was doing on what I called 'experienced utility' and 'remembered utility'. We did experiments in which participants were recording their experience of pain, or discomfort, or pleasure, second-by-second or minute-by-minute. We then compared the results with retrospective measures from the same participants, that is, when we asked them 'how did you feel?', or 'what was your total pleasure?', or 'total pain?' and so on. What we found was that the retrospective measures didn't necessarily correspond to what the participants had actually experienced. I noticed that the questions on wellbeing surveys are retrospective; they ask you how you have been. This led me to the distinction that I now refer to as the distinction between the 'remembering self' and the 'experiencing self'.

\section{What do you take "wellbeing" to mean?}

I distinguish between the 'experiencing self' and the 'remembering self'. The wellbeing of the 'experiencing self' is a subjective experience of living. The wellbeing of the 'remembering self' is how satisfied you are with your life when you think about it. It's a completely different kind of question for each 'self'. I used to think that wellbeing really meant 'experienced utility'. I don't think this can be sustained because it turns out that life satisfaction is extremely important to people - this is the goal that they are primarily interested in - so you can't have a measure of wellbeing that is not also responsive to what people want. So now I have what I call a 'hybrid model of wellbeing', in which I am interested in both.

\section{What is the most important wellbeing-related finding to date?}

Clearly the most important finding is that wellbeing has a large genetic component. If I had to pick one finding, to the best of what we know, certainly in 'experienced happiness', I'd pick that. There are data now, in the American Economic Review, which show that life satisfaction is quite heritable. Between $33 \%$ and $50 \%$ of the variance in life satisfaction has been genetically determined - that's the most important finding.

\section{What is the most important application of wellbeing research to our lives?}

There are applications done by consulting firms (e.g., Gallup) that record the wellbeing of employees in their place of work. Despite firms being primarily interested in productivity, this work encourages firms to try to maximise employee wellbeing. It turns out that there is a

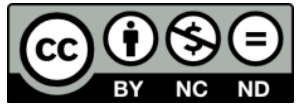


correlation between how much people like being at work (employee engagement) and productivity. That is the most important application to date, but of course there are others.

\section{What is the most important wellbeing-related finding from your research?}

The finding reported in the Proceedings of the National Academy of Sciences a few months ago (by Angus Deaton and myself) is the most important. We found that 'experienced happiness' in the United States levels off perfectly around $\$ 70,000-\$ 75,000$ income per annum. Life satisfaction, however, goes on increasing. That is the most important finding because it highlights the distinction between the two types of wellbeing.

\section{What are you working on right now?}

I'm still exploring the distinction between the two types of wellbeing. Several of us are also helping a group in the United Kingdom that is trying to set up a measure of wellbeing that could be used to guide policy. I am essentially working on the following question: are there measures of wellbeing that are sufficiently sensitive to changes in policy to be useful for guiding policy? It's quite uncertain because, by and large, what is impressive about national statistics is that they are very stable year-to-year. International differences are also very stable year-to-year. We are trying to understand whether there are any measures that are sensitive enough to pick up the effects of large changes in employment and unemployment, not among the unemployed or the people who have lost their jobs - that's obvious - but in the population at large. Gallup has many measures, so I'm working with Gallup and other senior scientists on this. We are investigating whether the measures that Gallup has are sensitive enough to perform this task.

\section{What do you think the next big thing in wellbeing research will be?}

The attempt to implement wellbeing measurements at the national level in several countries is the next big thing. If these attempts are unsuccessful, then the next big thing is going to be a major disappointment. I'm afraid that these measures are premature, that we don't know enough yet about what works and what doesn't. My biggest worry is that the public will see how little impact seemingly big circumstantial changes have on the different measures. This may turn them off the whole thing, which is my biggest worry.

\section{What are the main benefits of interdisciplinary research on wellbeing?}

The quality of research on wellbeing has improved measurably since top flight economists joined in substantial numbers. Angus Deaton (president of the American Economic Association last year), Alan Krueger, Richard Easterlin, and the like have clearly raised the level of sophistication in statistical analysis. The next thing that is happening is that geneticists and physiologists are going to add their input and the study of wellbeing will merge with the study of health and health statistics. To some extent this is already happening in the UK, or has been happening for a while (since the famous Whitehall studies). I think there will be major developments from that merger in the near future.

\section{What would the ideal census question on wellbeing be and why?}

I don't think there is a single ideal to answer this question. I would be firmly opposed to a single measure because there are at least two distinct kinds of wellbeing - emotional wellbeing and life satisfaction. Furthermore, in emotional wellbeing there is the distinction between 
positive and negative affect, which are not perfectly correlated. In fact they are quite imperfectly correlated. Therefore, if one is interested in the measure of suffering, which is what I would be most interested in and think is most relevant to society, then no single question would do.

\section{Author}

Aaron Jarden

Open Polytechnic of New Zealand

aaron.jarden@openpolytechnic.ac.nz

\section{References}

Kahneman, D. \& Deaton, A. (2010). High income improves evaluation of life but not emotional well-being. Proceedings of the National Academy of Sciences, 107(38), 16489-16493.

http://dx.doi.org/10.1073/pnas.1011492107 